\title{
Protective effect of soybean oil- or fish oil-rich diets on allergic airway inflammation
}

\author{
This article was published in the following Dove Press journal: \\ Journal of Inflammation Research \\ 19 May 2016 \\ Number of times this article has been viewed
}

\author{
Roberta Araujo Navarro- \\ Xavier' \\ Karina Vieira de Barros' \\ Iracema Senna de Andrade' \\ Zaira Palomino ${ }^{2}$ \\ Dulce Elena Casarini ${ }^{2}$ \\ Vera Lucia Flor Silveira ${ }^{3}$ \\ 'Departamento de Fisiologia, \\ ${ }^{2}$ Departamento de Medicina, \\ ${ }^{3}$ Departamento de Ciências Biológicas, \\ Universidade Federal de São Paulo, \\ Diadema, São Paulo, Brazil
}

Background: The increased prevalence of asthma and allergic diseases in westernized societies has been associated with increased intake of diets rich in $n-6$ fatty acids (FAs) and poor in n-3 FAs. This study aimed to analyze the prophylactic effects of treatment with a soybean oil-rich diet (rich in n-6) or fish oil (rich in n-3) in an allergic airway inflammation model on lung inflammation score, leukocyte migration, T-helper cell (Th)-2 (interleukin [IL]-4, IL-5) and Th1 (interferon [IFN]- $\gamma$, tumor necrosis factor- $\alpha$ ) cytokines, lipoxin A4, nitric oxide, bradykinin, and corticosterone levels in bronchoalveolar lavage (BAL) or lungs.

Methods: Male Wistar rats fed with soybean oil- or fish oil-rich diet or standard rat chow were sensitized twice with ovalbumin-alumen and challenged twice with ovalbumin aerosol. The BAL and lungs were examined 24 hours later.

Results: Both diets, rich in n-6 or n-3 FAs, impaired the allergic lung inflammation and reduced leukocyte migration, eosinophil and neutrophil percentages, and IL-4/IL-5/bradykinin levels in BAL and/or lungs, as well as increased the nitric oxide levels in BAL. The soybean oil-rich diet additionally increased the levels of lipoxin A4 and corticosterone in the lungs.

Conclusion: Data presented demonstrated that the n-6 FA-rich diet had protective effect upon allergic airway inflammation and was as anti-inflammatory as the n-3 FA-rich diet, although through different mechanisms, suggesting that both diets could be considered as complementary therapy or a prophylactic alternative for allergic airway inflammation.

Keywords: asthma, nitric oxide, n-6 fatty acids, n-3 fatty acids, cytokines, lipoxin A4, bradykinin

\section{Introduction}

Asthma is a chronic inflammatory disorder of the respiratory airways, characterized by a multicellular process involving mainly eosinophils, neutrophils, CD4+ T-lymphocytes, and mast cells, with eosinophilic infiltration being the most prominent feature. ${ }^{1}$ The physiopathology of allergic asthma is driven by an imbalance between the T-helper cell (Th)-1 and Th2 cytokines, favoring the Th2 profile. ${ }^{2}$ There is no cure for asthma and the first line of therapy in its management are the glucocorticoids, which have a broad spectrum of adverse effects, and some asthmatic patients are resistant to these drugs. Owing to this, many researchers have investigated new therapies. $^{3}$

It has been hypothesized that the increase in asthma and allergy prevalence in westernized societies over the past decades might be related to a combination of a higher intake of n-6 fatty acids (FAs), which is found in vegetable oils, and a lower intake of $\mathrm{n}-3$, which is found in marine oils. ${ }^{4,5}$ 
Given the competitive interplay between eicosanoids from n-3 FAs, which are less proinflammatory than those derived from n-6, and the fact that the n-3 metabolites have pro-resolution properties, it has been suggested that n-3 FA intake could improve asthma and Th2 diseases..$^{6-8}$ Thus, it has been recommended to increase the consumption of n-3 FAs and reduce the intake of $\mathrm{n}-6 \mathrm{FA}^{9,10}$ to minimize the adverse effects of excessive n-6 FAs. However, there is no clear evidence of the harmful effects of n-6 FA. Previous studies by our group ${ }^{11,12}$ have shown similar anti-inflammatory effects of diets enriched with fish (rich in n-3 FAs) or soybean (rich in n-6 FAs) oil in an acute inflammation model. In a chronic inflammation model, we observed that the mixture of fish and soybean oils in the diet was better than the use of fish oil as an exclusive source of fat. ${ }^{13,14}$

The metabolism of n- 6 or n-3 FAs generates several classes of eicosanoids that serve as bioactive mediators for the regulation of the airway tone and inflammation. The resolvins, n-3 FA compounds, are involved in the resolution of inflammation, demonstrating protective and regulatory roles in airway hyperresponsiveness and in asthma inflammation. ${ }^{15}$ On the other hand, lipoxins, eicosanoids from n-6 FA metabolism, are also relevant for the resolution phase in asthma, inhibiting eosinophil trafficking and polymorphonuclear leukocyte chemotaxis. ${ }^{16-18}$ In severe asthma, airway lipoxin A4 (LXA4) levels and expression of lipoxin biosynthetic enzymes and receptors are markedly decreased..$^{19}$ The corticosteroids, anti-inflammatory hormones widely used in asthma therapy, have been reported to have an interesting relationship with lipoxins, upregulating these pro-resolution lipid mediators. ${ }^{20}$

Given the known effects of n-3 and n-6 FAs on inflammatory response and asthma parameters, in addition to the data from our previous studies, ${ }^{12-14}$ we aimed to verify whether a diet rich in $\mathrm{n}-6$ FAs is able to induce a proinflammatory effect and be detrimental for the lung inflammation process, with a diet rich in n-3 FAs being anti-inflammatory and protective.

We analyzed the prophylactic effects of treatment with a diet rich in fish (rich in n-3 FAs) or soybean (rich in n-6 FAs) oil, before and during the induction of an allergic airway inflammation process, on the migration of eosinophils, neutrophils, and mononuclear cells in bronchoalveolar lavage (BAL), lung inflammation score, concentrations of interleukin-4 (IL-4), IL-5, tumor necrosis factor alpha (TNF- $\alpha$ ), interferon gamma (IFN- $\gamma$ ), LXA4, and corticosterone in the BAL and/or lungs. We also studied two other mediators, nitric oxide (NO) and bradykinin (Bk). Bk is a potent bronchoconstrictor in asthmatic patients ${ }^{21}$ and elicits NO release in the smooth muscle of the airways. ${ }^{22-24}$ The increased NO in the exhaled air of asthmatic patients modulates the bronchospasm caused by Bk and decreases bronchial edema and inflammation. ${ }^{25-27}$

\section{Materials and methods}

\section{Animals and diets}

All animal experiments were performed according to protocols approved by the Experimental Research Committee of Universidade Federal de São Paulo (Comissão de Ética no Uso de Animais [ethics committee] number 0743/06), in accordance with the standards established by the Brazilian Guidelines for Care and Use of Animals for Scientific Purposes and Teaching imposed by the National Council of Animal Experimentation-CONCEA, in 2013. ${ }^{28}$

Male Wistar rats aged 28-30 days were supplied by the Center for Development of Experimental Models of the Universidade Federal de São Paulo. They were maintained in collective polypropylene cages in an isolated room under controlled temperature $\left(23^{\circ} \mathrm{C} \pm 1^{\circ} \mathrm{C}\right)$, humidity $(60 \% \pm 5 \%)$, and lighting (12:12 hour light-dark cycle with lights on at 7 am) with free access to water and food. Rats were separated into three groups after they were weaned: control, soybean, and fish groups. The control group was fed a standard balanced rat chow with $4 \%$ fat and $20 \%$ protein (Nuvilab CR- $1^{\circledR}$; Nuvilab Produtos Agropecuarios, Ltd, Paraná, Brazil). The soybean and fish groups were fed soybean oil- and fish oilrich diets, respectively. These diets were prepared by adding $15 \%$ of soybean oil (Lisa, Cargill, SP, Brazil) or $15 \%$ of fish oil (Sigma Chemical Co, St Louis, MO) to standard rat chow. Casein (Labsynth, Diadema, Brazil) was added to both soybean oil- and fish oil-rich diets, to achieve $20 \%$ of protein. Caloric density of diets was determined using an adiabatic calorimeter IKA-C400 (Janke and Kunkel, IKA Werk, Staufen, Germany). The values were $17.4 \mathrm{~kJ} / \mathrm{g}$ for the standard chow and $20.5 \mathrm{~kJ} / \mathrm{g}$ for both the FA-rich diets. Once prepared, the diets were kept frozen until usage. The rats were provided with a fresh food cup every day, and both body weight and 24-hour food intake were monitored weekly. The FA composition of the diets was analyzed at the Nutrition Institute of Federal University of Rio de Janeiro (Table 1).

\section{Immunization protocol}

Allergen sensitization and challenge were carried out as previously described..$^{29}$ Briefly, after 4 weeks of feeding, all rats were actively sensitized by an intraperitoneal (ip) injection of a mixture containing $10 \mathrm{mg}$ of ovalbumin and $10 \mathrm{mg}$ of $\mathrm{Al}(\mathrm{OH})_{3}$ in saline (total volume of $0.7 \mathrm{~mL}$ ). A 
Table I Fatty acid composition (g/l00 g of diet) of control, soybean, and fish diets

\begin{tabular}{llll}
\hline Fatty acid & Control & Soybean & Fish \\
\hline $14: 0$ & 0.06 & 0.04 & 1.20 \\
I6:0 & 0.66 & 1.80 & 3.10 \\
I8:0 & 0.10 & 0.50 & 0.80 \\
16:I (n-7) & 0.004 & 0.015 & 1.20 \\
I8:I (n-9) & 0.80 & 3.43 & 1.65 \\
I8:2 (n-6) & 2.12 & 8.08 & 2.16 \\
18:3 (n-3) & 0.13 & 0.81 & 0.39 \\
20:5 (n-3) & 0.002 & 0.011 & 2.11 \\
22:6 (n-3) & 0.01 & 0.004 & 1.54 \\
Saturated & 0.82 & 2.34 & 5.10 \\
Monounsaturated & 0.80 & 3.43 & 1.65 \\
Polyunsaturated & 2.26 & 8.90 & 6.20 \\
n-6 Polyunsaturated & 2.12 & 8.08 & 2.16 \\
n-3 Polyunsaturated & 0.14 & 0.82 & 4.04 \\
n-6: n-3 ratio & 15.14 & 9.85 & 0.53 \\
\hline
\end{tabular}

second sensitization was given 7 days later. At 14 days and 21 days after the first sensitization, control, soybean, and fish groups were challenged by exposure to an aerosol of ovalbumin (grade II; Sigma Chemical Company, St. Louis, MO, USA) solution $(2.5 \% \mathrm{w} / \mathrm{v})$, generated by an ultrasonic nebulizer (ICEL US-800, SP, Brazil) delivering particles of $0.5-10 \mathrm{~mm}$ diameter at $\sim 0.75 \mathrm{~mL} / \mathrm{min}$ for 20 minutes. The animals were euthanized 24 hours after the last antigen challenge via an ip injection of ketamine/xylazine, and the BAL and lungs were collected.

\section{Total and differential cell counts in BAL}

Twenty-four hours after the last antigen challenge, the animals were anesthetized and killed by injecting ketamine/ xylazine $(1: 1, i p)$ and their tracheae were cannulated with a polyethylene tube connected to a syringe. The airways were washed three times with $4 \mathrm{~mL}$ of phosphate-buffered saline (PBS, $\mathrm{pH} 7.4$, at $4^{\circ} \mathrm{C}$ ). The BAL was recovered and centrifuged at $2,400 \times g$ for 10 minutes. The supernatants were kept at $-80^{\circ} \mathrm{C}$ for BAL determinations and the cell pellets were resuspended in $0.5 \mathrm{~mL}$ of PBS. One volume of a solution containing $0.5 \%$ crystal violet dissolved in $30 \%$ acetic acid was added to nine volumes of the cell suspension. Total cell number was determined with the aid of a Neubauer chamber. Differential cell count was performed in BAL preparations stained with hematoxylin and eosin (Instant Prov Kit; Newprov, Pinhais, Paraná, Brazil) upon cytocentrifugation at $500 \times g($ Cytospin 3 ; Shandon Southern Instruments, Sewickley, PA, USA). A minimum of 400 cells were counted and classified as neutrophils, eosinophils, or mononuclear cells based on morphologic criteria.

\section{Lung analysis}

For the biochemical determinations in the lung tissue, after collecting the BAL, the right lung was removed and homogenized in $8.0 \mathrm{~mL}$ of cold PBS, centrifuged at $500 \times \mathrm{g}$ for 10 minutes at $4{ }^{\circ} \mathrm{C}$, and kept at $-80^{\circ} \mathrm{C}$ for future determinations. The left lung was also removed and fixed for 24 hours in $10 \%$ paraformaldehyde solution. The organ was then cut into small fragments, dehydrated through an ethanol series (70\%-100\%), cleared in xylol, and embedded in paraffin. The fragments were sliced into $5 \mu \mathrm{m}$ thick sections and stained with hematoxylin-eosin.

Histopathological evaluation, performed by a pathologist blinded to the protocol design, was based on the intensity of the inflammatory infiltrate in randomly selected areas around the vessels and bronchioles and was scored as 0 (no inflammatory cells), 1 (few cells), 2 (moderate cell infiltration), and 3 (large number of inflammatory cells), assuming a linear relationship between the amount of inflammation and inflammatory score.

\section{TNF- $\alpha$, IFN- $\gamma$, IL-4, LXA4, and corticosterone determinations in BAL and lungs}

Enzyme-linked immunosorbent assay kits were used to measure TNF- $\alpha$, IFN- $\gamma$, IL-4 (R\&D Systems, Inc., Minneapolis, MN), LXA4 (US Biological Life Science, Salem, MA, USA), and corticosterone (Cayman Chemical, Ann Arbor, MI, USA) in BAL and lung tissues, according to the manufacturer's instructions.

\section{Immunohistochemistry for IL-5}

For the immunoreactive determination of IL-5 in the lung tissue, the animals were "anesthetized and killed by injecting ketamine/xylazine (1:1, ip) 24 hours after the last challenge, transcardially perfused with $50 \mathrm{mM}$ PBS, and fixed with $4 \%$ paraformaldehyde in $100 \mathrm{mM}$ PBS $(\mathrm{pH} 7.4)$ at $4{ }^{\circ} \mathrm{C}$. The left lung was removed, fixed in the fixative solution (4\% paraformaldehyde in $100 \mathrm{mM} \mathrm{PBS}, \mathrm{pH} \mathrm{7.4}$, at $4^{\circ} \mathrm{C}$ ) overnight, and transferred to $30 \%$ sucrose in PBS for cryoprotection. The lung was sectioned into $45 \mu \mathrm{m}$ thick sections with a freezing microtome, and two sections were selected and processed for IL-5 immunohistochemistry. The tissue sections were rinsed in PBS, incubated in $3 \% \mathrm{H}_{2} \mathrm{O}_{2}$ for 15 minutes to block the endogenous peroxidase activity, and afterwards incubated in blocking solution (5\% albumin and $0.3 \%$ Triton X-100 in PBS) for 2 hours, followed by incubation in goat anti-IL-5 antibody ( $1 \mu \mathrm{g} / \mathrm{mL}$; R\&D Systems, Inc.) for 48 hours at $4^{\circ} \mathrm{C}$. Then, the tissues were incubated for 90 minutes in rabbit anti-goat biotinylated secondary antibody (1:500; Sigma) 
diluted in PBS with 2.5\% albumin and $0.3 \%$ Triton X-100. The tissues were subsequently incubated with avidin-biotinhorseradish peroxidase complex (1:500; Vector Laboratories; Burlingame, CA, USA) diluted in PBS for 90 minutes at room temperature. The immunoreactivity was visualized by incubating the sections in $0.01 \% 3,3^{\prime}$-diaminobenzidine tetrahydrochloride (Sigma-Aldrich Co., St Louis, MO) and $0.03 \% \mathrm{H}_{2} \mathrm{O}_{2}$ in PBS plus $0.03 \%$ of nickel ammonium sulfate to intensify the reaction product. When the staining was sufficient, as established by microscopic examination, the reaction was stopped by rinsing in PBS. The sections were mounted on gel-coated slides and cover-slipped with DPX (Sigma Aldrich; St. Louis, MO, USA). Negative controls were set up by eliminating the primary antibody from the protocol, which resulted in absence of staining.

\section{Analysis of immunohistochemistry staining}

Staining analysis was performed using a light microscope (Eclipse E600; Nikon Corporation, Tokyo, Japan) connected to a digital camera (CCD video camera; Exwave HAD ${ }^{\circledR}$; Sony, SP, Brazil). Two areas in each section were analyzed, the alveolar and the peribronchiolar. All the positive cells were quantified with the use of a graded bar mounted at the ocular level and expressed as the number of positive cells per square millimeter (cell number $/ \mathrm{mm}^{2}$ ). The final result, expressed as the number of positive cells per square millimeter (cell number $/ \mathrm{mm}^{2}$ ), was calculated as the average of all cellular counts performed in two bronchial sections. The boundaries of the lung structures were based on the Nissl-stained slice.

\section{Quantification of Bk}

Protease inhibitors were added immediately following collection of BAL and lung tissues to final concentrations of $5 \mathrm{mM}$ ethylenediaminetetraacetic acid, $1 \mathrm{mM}$ phenylmethylsulfonyl fluoride, $1 \mathrm{mM}$-hydroxymercuribenzoate, $1.5 \mathrm{mM}$ $o$-phenanthroline, and $1 \mu \mathrm{M}$ pepstatin. Lung tissue samples were frozen in liquid nitrogen and stored at $-80^{\circ} \mathrm{C}$, as were the BAL samples, until further analysis. For extraction of Bk, $2 \mathrm{~mL}$ of BAL or lung tissue was loaded on a Sep-Pak C18 cartridge (Waters Corporation, Milford, MA, USA), which had been equilibrated in $5 \%$ acetonitrile and $0.1 \% \mathrm{H}_{3} \mathrm{PO}_{4}$. The cartridges were eluted with $3 \mathrm{~mL}$ of $35 \%$ acetonitrile in $0.1 \% \mathrm{H}_{3} \mathrm{PO}_{4}$. The prepurified extracts were dried in a SpeedVac concentrator (BOC Edwards; Edwards Brazil, SP, Brazil), resuspended in $500 \mu \mathrm{L}$ of $0.1 \% \mathrm{H}_{3} \mathrm{PO}_{4}$ containing $5 \%$ acetonitrile (phase A), and then used for high-performance liquid chromatography. For chromatographic identification and quantification of $\mathrm{Bk}, 100 \mu \mathrm{L}$ of the extracted sample was injected into an high-performance liquid chromatography system (Milton Roy Co., Rochester, NY, USA), and the separation was performed through a reverse-phase RP18 Brownlee column $(4.6 \times 250 \mathrm{~mm}$; EMD Millipore, Billerica, MA) equilibrated with $0.1 \% \mathrm{H}_{3} \mathrm{PO}_{4}$ containing $5 \%$ acetonitrile (phase A). After 5 minutes of isocratic elution, the peptides were eluted with $0 \%-35 \%$ linear gradient (v/v) of $90 \%$ acetonitrile in $0.1 \% \mathrm{H}_{3} \mathrm{PO}_{4}$ (phase $\mathrm{B}$ ) developed for 20 minutes at a flow rate of $1.5 \mathrm{~mL} / \mathrm{min}$. The effluent was monitored by absorbance at $214 \mathrm{~nm}$. Bk was identified by elution position and quantified by peak area integration using synthetic Bk as a standard.

\section{Determination of NO}

NO was determined in the BAL and lung tissues by the chemiluminescence method. ${ }^{30}$ We used the Model 280 Nitric Oxide Analyzer from Sievers Instruments, Inc (Boulder, CO), a high-sensitivity detector for measuring NO, based on a gas phase chemiluminescent reaction between NO and ozone. The emission from electrically excited nitrogen dioxide is in the red and near-infrared regions of the spectrum, and it is detected by a thermoelectrically cooled red-sensitive photomultiplier tube. The sensitivity for measuring NO and its reaction products in liquid samples is $\sim 1 \mathrm{pM}$.

\section{Statistical analysis}

Data are expressed as the mean \pm standard error of the mean. Statistical analysis was performed using GraphPad Prism V5 (Graphpad Software, Inc. La Jolla, CA, USA). Variables of the three groups were compared using nonparametric Kruskal-Wallis analysis of variance test, and multiple comparisons were made using Dunn`s multiple comparison test. Significance level was set at $P<0.05$.

\section{Results}

\section{Food intake and body weight}

Food intake of the fish and soybean groups was lower than that of the control group throughout the entire experimental period, but the energy intake and body weight did not significantly differ among the groups (data not shown).

\section{Total and differential cell counts, histopathological analysis, and lung inflammation score}

Treatment with n-3 or n-6 FA-rich diets inhibited the allergic airway inflammation by decreasing the total and differential cell counts in BAL (Figure 1) in relation to the control group. 
A
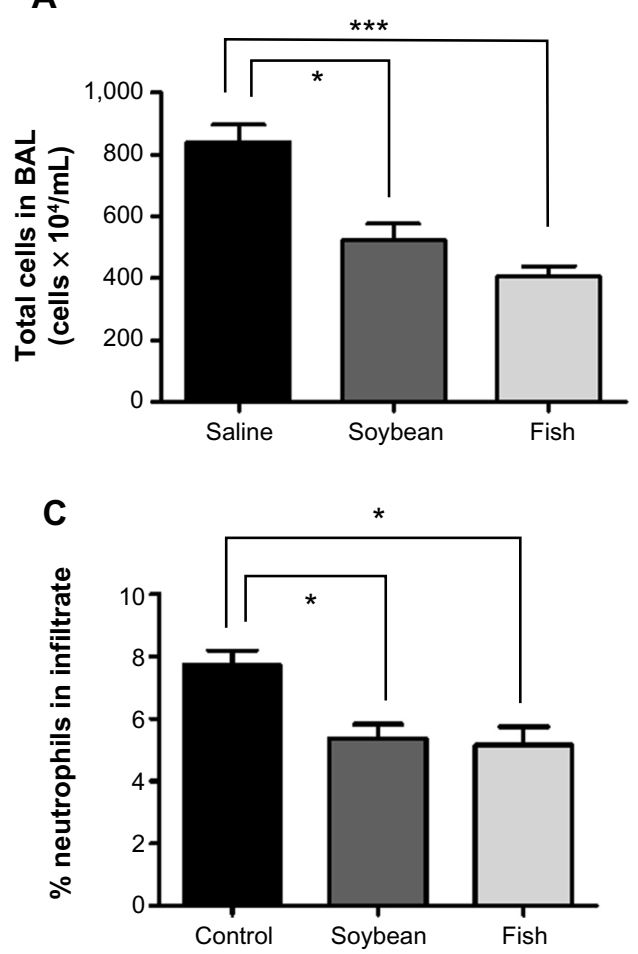
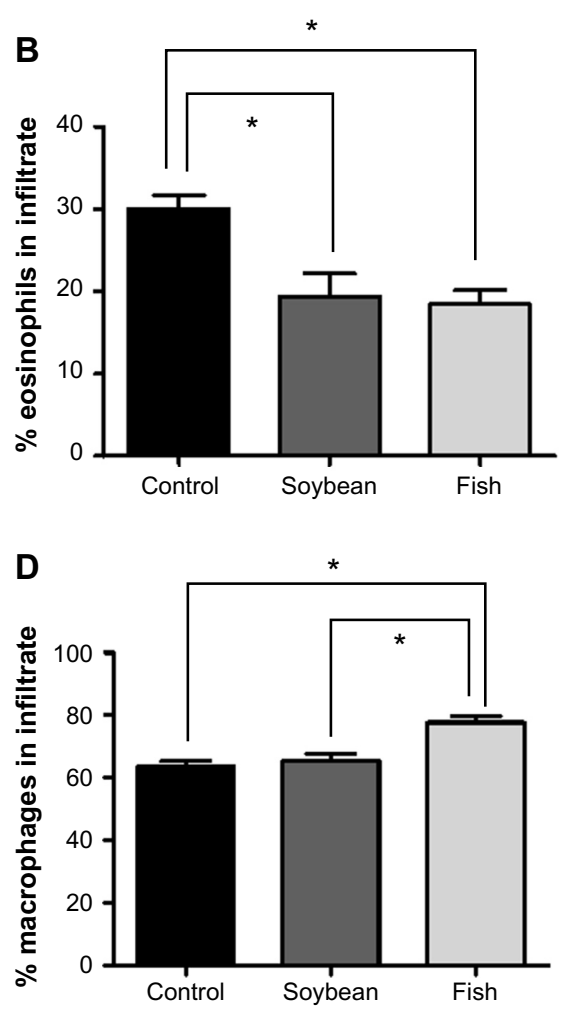

Figure I Total number of cells (A) and percent of eosinophils (B), neutrophils (C) and macrophages (D) in BAL from control, soybean, and fish groups. Note: Values are expressed as mean \pm SEM; $n=14-16$ per group. $* P<0.05, * * * p<0.001$.

Abbreviations: BAL, bronchoalveolar lavage; SEM, standard error of the mean.

A significant decrease in the total number of cells in BAL was evident, with a decrease of $38 \%$ for the soybean and $52 \%$ for the fish group compared to control. A marked decrease was found in the eosinophil percentage (36\% and 39\% for soybean and fish groups, respectively) and in the neutrophil percentage (30\% and 33\% for soybean and fish groups, respectively) relative to the control group. Only the fish group was able to increase mononuclear cell percentage compared to control and soybean groups. These results are in parallel with the histopathological analysis of the lung sections, which showed the efficiency of both diets in reducing the allergic airway inflammation, as depicted in Figure 2. The analysis of stained lung slides revealed a marked influx of inflammatory cells around the small vessels and bronchi of the control group. The treatment with soybean oil- or fish oil-rich diets strongly reduced this cellular infiltration. There was a clear decrease in the lung inflammation score in the soybean and fish groups in comparison to the control group.

\section{ThI and Th2 cytokines}

To identify the mechanisms by which fish oil- or soybean oilrich diets regulate the inflammatory response, we measured the levels of some Th1 and Th2 cytokines that play important roles in the chronic inflammation process of allergy: IL-4 and IL-5 as Th2 and IFN- $\gamma$ and TNF- $\alpha$ as Th1 cytokines. Compared with the control diet, fish oil- or soybean oil-rich diets impaired the levels of IL-4 in the BAL and lungs, 24 hours after the last challenge (Figure 3). IL-5 was significantly decreased in lung alveolar and peribronchiolar areas of the soybean group compared to the control group. The fish oil-rich diet also decreased IL-5 in the lung alveolar area (Figure 3). The levels of the Th1 cytokine, IFN- $\gamma$, and TNF- $\alpha$ in the BAL and lungs were not changed by the diets (Figure 3 ).

\section{$\mathrm{Bk}$ and $\mathrm{NO}$}

Both soybean oil- and fish oil-rich diets reduced the Bk concentration in the lungs (Figure 4), while no detectable levels were found in BAL (data not shown). No differences in the NO levels were observed in the lungs, whereas in BAL, $\mathrm{NO}$ concentrations were increased in both fish and soybean groups in relation to the control (Figure 4).

\section{LXA4 and corticosterone}

The corticosterone levels in the lungs were markedly increased in the soybean group compared to the control and fish groups (Figure 5). LXA4 levels in BAL did not differ among the groups, while the lungs of the soybean group showed increased LXA4 levels compared to control (Figure 5). 

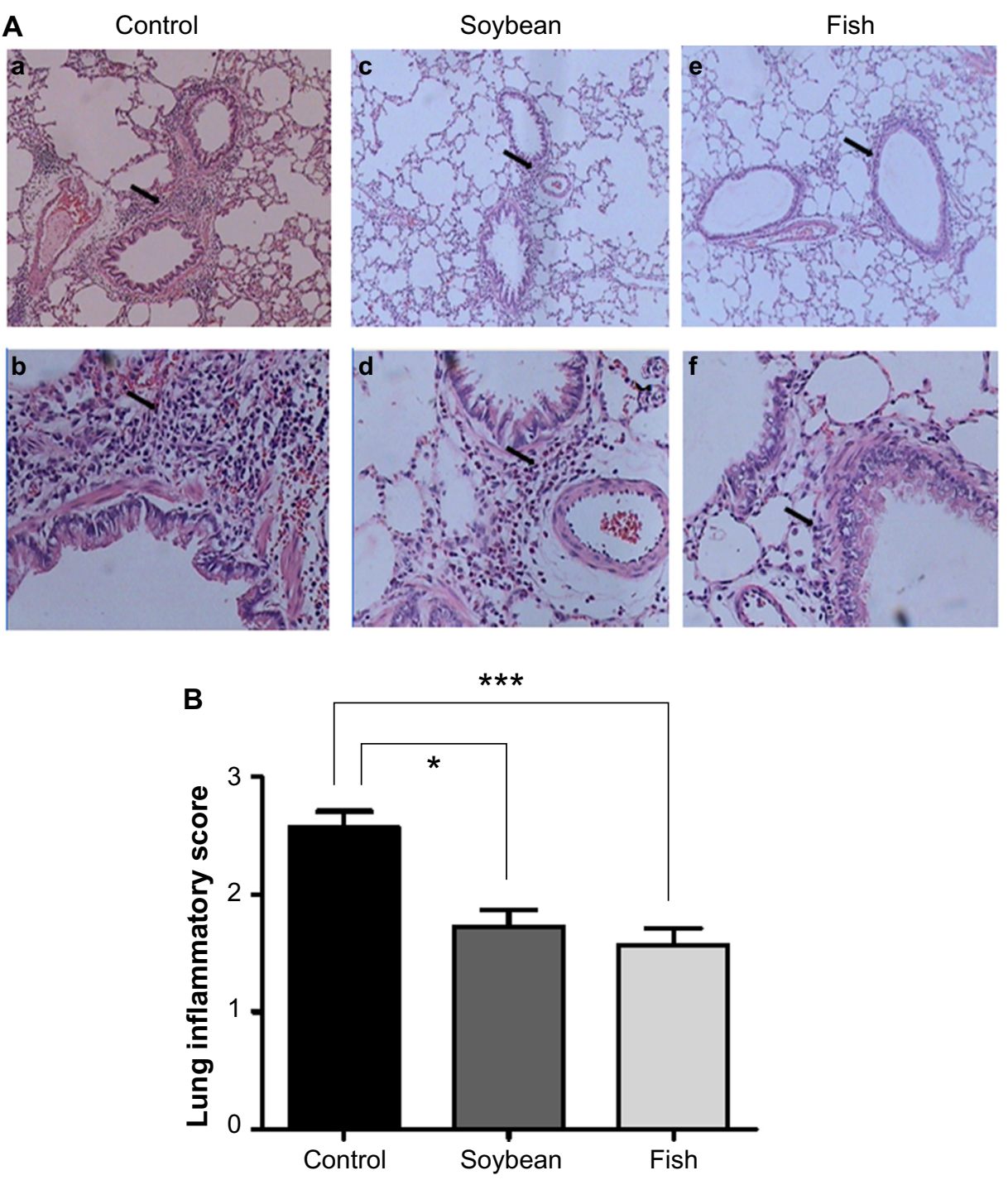

Figure 2 Photomicrography of the lungs of rats from control, soybean, and fish groups.

Notes: In (A), observe the intense peribronchial inflammatory reaction composed predominantly of eosinophils and mononuclear cells (arrows) in the control group (a, b). In soybean (c, d) and fish (e, f) groups, the peribronchial inflammatory infiltrate is reduced (arrows). Hematoxylin-eosin staining. Original magnifications: $\times 100$ (a, $c$, and e); $\times 400$ (b, d, and f). In (B), lung inflammatory score from control, soybean, and fish groups is shown. Values are expressed as mean $\pm S E M$; $n=\mid 4-16$ per group. $* P<0.05$, $* * * p<0.001$.

Abbreviation: SEM, standard error of the mean.

\section{Discussion}

Here we have studied the prophylactic effects of fish oil- or soybean oil-rich diets on allergic lung inflammation using a well-established experimental model that presents many of the characteristic features of allergic asthma. ${ }^{29,31,32}$

The diets enriched with either soybean oil or fish oil decreased food intake but did not change the energy intake and the body weight gain. These findings are in agreement with data from other laboratories ${ }^{11}$ and our previous studies, ${ }^{12}$ indicating a higher efficiency of dietary lipid, probably due to the lower energetic cost of lipid deposition..$^{33}$

Our data show that the soybean oil-rich diet did not exert a proinflammatory effect. On the contrary, this diet as well as the fish oil-rich diet definitely induced an anti-inflammatory effect and protected the animals from the allergic airway inflammation by reducing the migration of total leukocytes, neutrophils, and eosinophils. The histopathological analysis and lung inflammation score noticeably confirmed this effect.

The reduction in BAL total cell count induced by the diets was more significant in the fish group. The fish diet also increased the mononuclear cell percentage in the bronchoalveolar infiltrate relative to the soybean and control diets. We speculate that this could be partly due to the action of resolvins; pro-resolution eicosanoids produced from eicosapentaenoic acid (EPA), an n-3 FA that stimulates the nonphlogistic infiltration of mononuclear cells; as well as stimulating macrophages to clear dying and apoptotic polymorphonuclear cells..$^{34,35}$ 

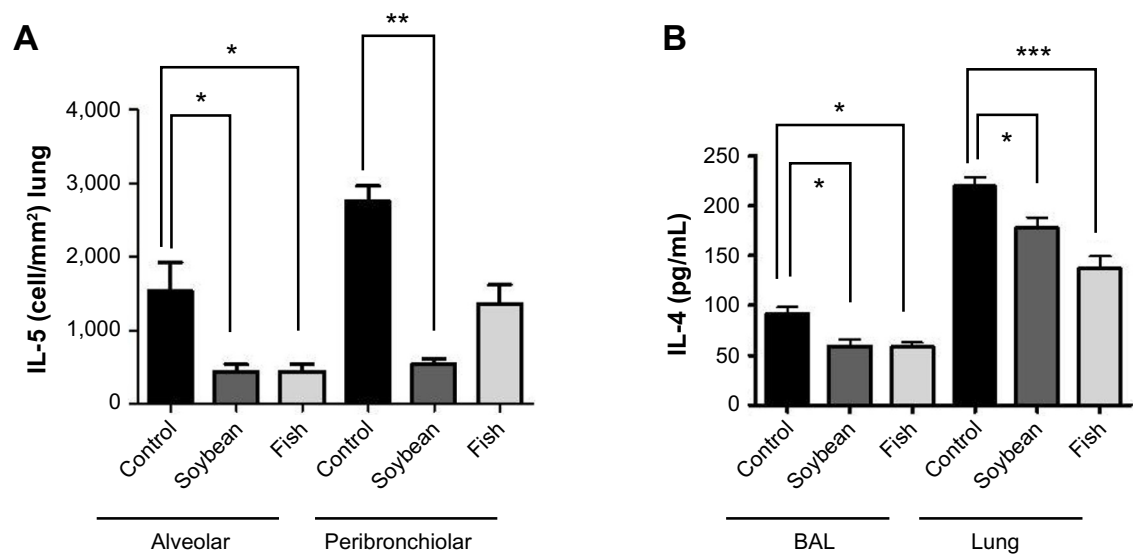

C

\begin{tabular}{ccccc}
\hline \multicolumn{5}{c}{ Th1 cytokines $(\mathrm{pg} / \mathrm{mL})$} \\
\hline & IFN- $\gamma$ & TNF- $\alpha$ & IFN- $\gamma$ & TNF- $\alpha$ \\
& BAL & BAL & Lung tissue & Lung tissue \\
& & $58.48 \pm 8.24$ & $59.69 \pm 5.35$ & $322.40 \pm 23.47$ \\
Control & nd & $(n=12)$ & $(n=11)$ & $(n=12)$ \\
& & $52.36 \pm 7.21$ & $53.47 \pm 5.48$ & $292.11 \pm 23.13$ \\
Soybean & nd & $(n=12)$ & $(n=12)$ & $(n=10)$ \\
& & $54.93 \pm 8.10$ & $47.35 \pm 3.80$ & $286.30 \pm 14.73$ \\
Fish & nd & $(n=10)$ & $(n=11)$ & $(n=12)$ \\
& & & &
\end{tabular}

Figure 3 Quantification of IL-5 (A), IL-4 (B), IFN- $\gamma$, and TNF- $\alpha(\mathbf{C})$ in lung and/or BAL from control, soybean, and fish groups. Note: Values are expressed as mean $\pm S E M ; n=10-12$ per group. ${ }^{*} P<0.05,{ }^{*} * P<0.01$, ${ }^{*} * * P<0.001$.

Abbreviation: IL, interleukin; IFN, interferon; TNF, tumor necrosis factor; SEM, standard error of the mean; BAL, bronchoalveolar lavage; nd, not detectable.

A

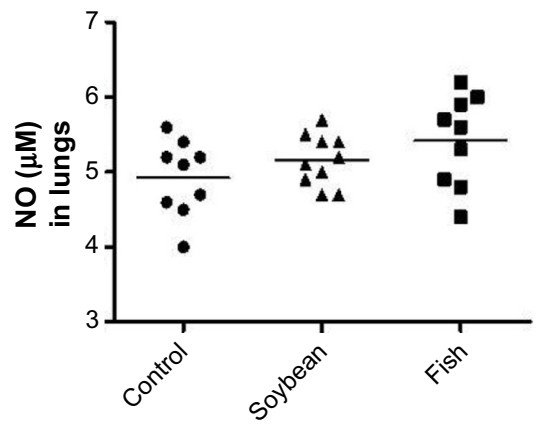

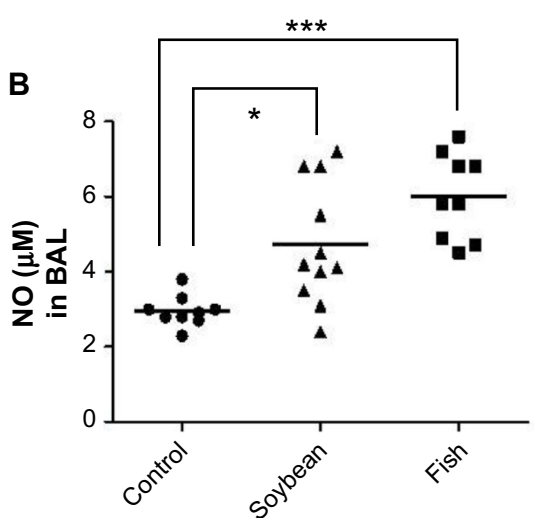

$\star \star *$

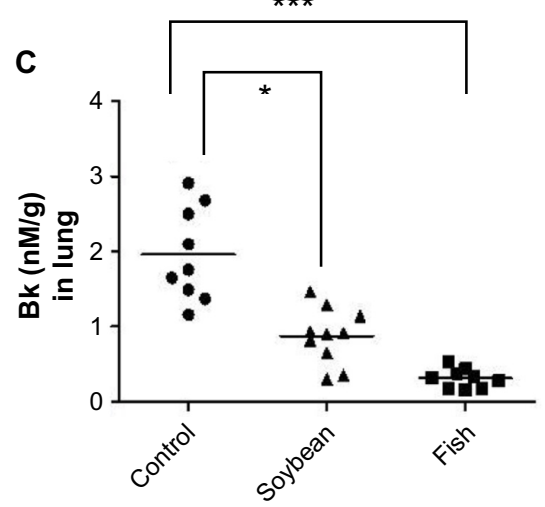

Figure 4 Concentrations of $\mathrm{NO}$ in lung $(\mathbf{A})$ and $\mathrm{BAL}(\mathbf{B})$ and $\mathrm{Bk}$ in lung $(\mathbf{C})$ from control, soybean, and fish groups. Note: Values are expressed as mean \pm SEM; $n=8-10$ per group. $* p<0.05, * * * p<0.001$.

Abbreviations: NO, nitric oxide; BAL, bronchoalveolar lavage; Bk, bradykinin; SEM, standard error of the mean. 
A

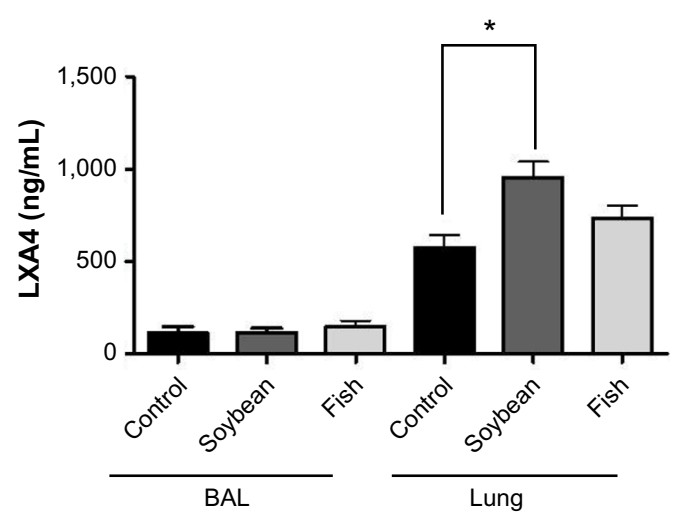

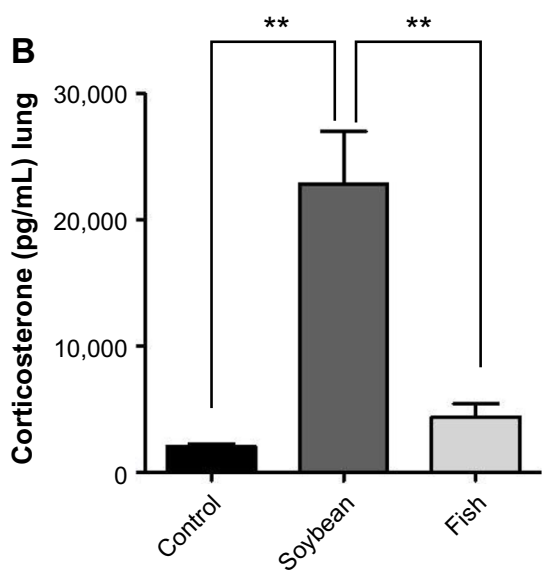

Figure 5 Concentrations of LXA4 in BAL and lung (A), as well as corticosterone in lung (B), from control, soybean, and fish groups. Note: Values are expressed as mean \pm SEM; $n=8-15$ per group. $* P<0.05, * * P<0.001$.

Abbreviation: LXA4, lipoxin A4; BAL, bronchoalveolar lavage; SEM, standard error of the mean.

Accordingly, it has been shown that the FA composition of inflammatory cells can be modified by increasing the intake of fish oil and this occurs in a dose-response manner and over a period of days to weeks. ${ }^{36}$ The increased membrane content of EPA and docosahexaenoic acid results in a changed pattern of production of eicosanoids and resolvins. ${ }^{36}$ In a recent publication, ${ }^{37}$ we demonstrated, in Wistar rats, that fish oil by gavage $(0.2 \mathrm{~g} / \mathrm{kg} / \mathrm{d})$ for only three consecutive days resulted in an increase in the content of EPA in plasma phosphatidylcholine and the liver. Intravenous supplementation with fish oil-based lipid emulsion during this short time period was more efficient, resulting in higher levels of EPA, docosahexaenoic acid, and total n-3 polyunsaturated FAs in plasma phosphatidylcholine, white blood cells, and liver. ${ }^{37}$ Moreover, González-Périz et al, ${ }^{38}$ using a lipidomic analysis with liquid chromatography/tandem mass spectrometry of adipose tissue from $o b / o b$ mice (an obesity model of insulin resistance and fatty liver disease) demonstrated that n-3 polyunsaturated FA-rich diet triggered the formation of n-3 FA-derived resolvins and protectins.

The Th 2 cytokine, IL-5, an important growth and migratory factor for eosinophils ${ }^{39}$ correlated with eosinophilia in asthmatic patients, ${ }^{40}$ was decreased in the lung alveolar area of both fish and soybean groups, which was in agreement with the reduced eosinophilia observed in these animals. IL-4, another Th2 cytokine that plays a role in eosinophilic inflammation, ${ }^{41}$ was also reduced by both diets. The reduction of these Th2 cytokines probably promoted the reduction of eosinophilia, contributing to the anti-inflammatory effect of the diets. On the other hand, no changes were seen in the Th1 cytokine, IFN- $\gamma$, and TNF- $\alpha$. These findings collectively indicate that both diets promoted their anti-inflammatory effects at least in part by decreasing the Th2 response.

Both diets also decreased lung Bk concentration, this inhibitory effect being more significant in the fish group. This could be an important anti-inflammatory mechanism of both oils because $\mathrm{Bk}$ is involved in the relevant actions leading to airway pathophysiology, such as bronchoconstriction, plasma protein extravasation, mucus secretion, and stimulation of inflammatory cells. ${ }^{42,43}$ In a model of acute inflammation, we previously observed reduced Bk concentration in the inflammatory exudate, which was induced by diets rich in fish oil or soybean oil. ${ }^{11}$ These decreased Bk levels were associated with the reduced amidolytic activity of plasma kallikrein (KK) induced by the diets. In this study, it is possible that the reduced Bk levels also are associated with reduced activity of $\mathrm{KK}$ or may even be associated with reduction of kininogen levels, because Bk is a product of kininogen cleavage by KK. In allergic airway inflammation, this inhibitory effect of the n-3- or n-6-rich diets on Bk has not yet been demonstrated, to the best of our knowledge.

As $\mathrm{Bk}$ induces bronchoconstriction and reduction in exhaled NO in asthmatic subjects, ${ }^{44}$ it is possible that the reduced Bk levels in our study could be associated with the increased NO levels in BAL, induced by both experimental diets. Then, the bronchodilator and bronchoprotective effects of $\mathrm{NO}^{45}$ probably also contributed toward the observed antiinflammatory effect.

The concentration of corticosterone, an anti-inflammatory hormone that has important functions in allergic lung inflammation, was noticeably higher in the soybean group. It has been shown that glucocorticoids can induce the expression 
of the LXA4 receptor ${ }^{33}$ and annexin A1, ${ }^{46,47}$ both mediators of the inflammation resolution process. In this context, the interaction between annexin A1 and the LXA4 receptor has a role in controlling leukocyte apoptosis and clearance by macrophages. ${ }^{48,49}$ In this way, it is possible that the elevated corticosterone levels found in the soybean group could be upregulating the LXA4 receptor and promoting a better effect of LXA4. This eicosanoid plays an important role in the resolution phase of the inflammatory process, with antiinflammatory and pro-resolution actions in lung inflammation models, being also counterregulatory to the cysteinyl leukotrienes and leukotriene B4. ${ }^{50}$ Therefore, some studies have suggested that LXA4 deficiency in asthmatic patients can contribute to chronic inflammation in asthma. ${ }^{51} \mathrm{In}$ this regard, it was demonstrated recently that the endogenous production of lipoxins can be influenced by diets rich in n-6 FAs that increased LXA4 levels in the intestine of mice and provided significant protection against intestinal ischemia/ reperfusion injury. ${ }^{52}$

Indeed, our results showed that the soybean oil-rich diet increased the LXA4 levels in the lungs in relation to the control diet. In BAL, the LXA4 concentrations were lower and not different among the groups, probably due to the dilution of samples.

In this study, the two FA-rich diets showed antiinflammatory effects, probably by different mechanisms, because only the soybean oil-rich diet was able to increase the levels of corticosterone and LXA4 in the lungs, potent agonists for the resolution of lung inflammation and of interest for asthma therapy. To the best of our knowledge, these effects of these diets have also not yet been demonstrated.

Mickleborough $^{53}$ has stated that the typical Western diet rich in n-6 FAs (20- to 25 -fold more n- 6 than n-3 FAs) can be a contributing factor to the increased incidence of asthma in Western societies. On the other hand, Sala-Vila et al ${ }^{54}$ did not support the hypothesis that atopy is associated with high n-6 and low n-3 FA status, suggesting that a combination of both may be most efficacious. Our results are in line with this reasoning, because we did not find a proinflammatory effect of the n-6-rich diet. Rather, the soybean oil-rich diet tested here was as anti-inflammatory as the fish oil-rich diet, although by different mechanisms. The analysis of FA composition of the two diets showed a n-6:n-3 ratio of 9.8:1 in the soybean oil-rich diet and 15.1:1 in the control diet, suggesting that it is not necessary to have a dramatic reduction in the n-6 FA content, as the literature recommends, because our soybean group had an evident anti-inflammatory effect in relation to control. The n- $6: n-3$ ratio appears to be crucial to the anti- or proinflammatory effects. So care should be taken when talking that $\mathrm{n}-6$ rich diets are harmful.

The relation with other FAs is certainly also important, because both FA-rich diets tested here had higher concentrations of monounsaturated and saturated FAs than the control diet.

Our results show that prophylactic intake of soybean oilor fish oil-rich diet impairs the allergic lung inflammation in sensitized antigen-challenged rats using mechanisms that are associated with downregulation of leukocyte migration, eosinophil and neutrophil percentages, and IL-5/IL-4/Bk levels in the BAL and/or lungs, as well as upregulation of $\mathrm{NO}$ levels in the BAL. The prophylactic intake of soybean oil-rich diet additionally upregulated the levels of corticosterone and LXA4 in the lungs.

\section{Conclusion}

In summary, this study shows that both soybean oil- and fish oil-rich diets have anti-inflammatory effects in the allergic lung inflammation model mediated by different mechanisms and could be considered as complementary therapy or a prophylactic alternative for allergic airway inflammation.

\section{Acknowledgments}

This study was supported by Fundação de Amparo à Pesquisa do Estado de Sao Paulo (2006/57075-9), Conselho Nacional de Desenvolvimento Científico e Tecnológico (302213/2010-4), and Coordenação de Aperfeiçoamento de Pessoal de Nível Superior. We also thank Maria Alice Castro for histopathologic evaluation, as well as Elisa MS Higa, Fernanda B Fernandes, and Magaret G Mouro for technical assistance in the bradykinin and nitric oxide measurements.

\section{Disclosure}

The authors report no conflicts of interest in this work.

\section{References}

1. Kay AB. The role of eosinophils in the pathogenesis of asthma. Trends Mol Med. 2005;11:148-152.

2. Hamid Q, Tulic M. Immunobiology of asthma. Annu Rev Physiol. 2009;71:489-507.

3. Durrani SR, Viswanathan RK, Busse WW. What effect does asthma treatment have on airway remodeling? Current perspectives. J Allergy Clin Immunol. 2011;128:439-448.

4. Black PN, Sharpe S. Dietary fat and asthma: is there a connection? Eur Respir J. 1997;10:6-12.

5. Devereux G. The increase in the prevalence of asthma and allergy: food for thought. Nat Rev Immunol. 2006;6:869-874.

6. Wu D, Meydani SN. W-3 polyunsaturated fatty acids and immune function. Proc Nutr Soc. 1998;57:503-509.

7. Wong KW. Clinical efficacy of n-3 fatty acid suplementation in patients with asthma. JAm Diet Assoc. 2005;105:98-105. 
8. Devereux G, Seaton A. Diet as a risk factor for atopy and asthma. J Allergy Clin Immunol. 2005;115:1109-1117.

9. Horrobin DF. Low prevalences of coronary heart disease (CHD), psoriasis, asthma and rheumatoid arthritis in Eskimos: are they caused by high dietary intake of eicosapentaenoic acid (EPA), a genetic variation of essential fatty acid (EFA) metabolism or a combination of both? Med Hypotheses. 1987;22:421-428.

10. Simopoulos AP. The importance of the omega-6/omega- 3 fatty acid ratio in cardiovascular disease and other chronic diseases. Exp Biol Med. 2008;33:674-688.

11. Wohlers M, Xavier RA, Oyama LM, et al. Effect of fish or soybean oil-rich diets on bradykinin, kallikrein, nitric oxide, leptin, corticosterone and macrophages in carrageenan stimulated rats. Inflammation. 2005;29(2-3):81-89.

12. Silveira VL, Limãos EA, Nunes DW. Participation of the adrenal gland in the anti-inflammatory effect of polyunsaturated diets. Mediators Inflamm. 1995;4:359-363.

13. Barros KV, Xavier RA, Abreu GG, et al. Soybean and fish oil mixture increases IL-10, protects against DNA damage and decreases colonic inflammation in rats with dextran sulfate sodium (DSS) colitis. Lipids Health Dis. 2010;8:1-9.

14. Barros KV, Abreu GG, Xavier RA, et al. Effects of a high fat or a balanced omega 3/omega 6 diet on cytokines levels and DNA damage in experimental colitis. Nutrition. 2011;27:221-226.

15. Haworth O, Cernadas M, Yang R, Serhan CN, Levy BD. Resolvin E1 regulates interleukin 23 , interferon- $\gamma$ and lipoxin $\mathrm{A} 4$ to promote the resolution of allergic airway inflammation. Nat Immunol. 2008;9(8):873-879.

16. Nijkamp FP, Van Der Linde HJ, Folkerts G. Nitric oxide synthesis inhibitors induce airway hyperresponsiveness in the guinea pig in vivo and in vitro. Am Rev Respir Dis. 1993;148:727-734.

17. Soyombo O, Spur BW, Lee TH. Effects of lipoxin A4 on chemotaxis and degranulation of human eosinophils stimulated by platelet-activating factor and N-formyl-Lmethionyl- L-leucyl-L-phenylalanine. Allergy. 1994;49:230-234.

18. Levy BD, De Sanctis GT, Devchand PR, et al. Multipronged inhibition of airway hyper-responsiveness and inflammation by lipoxin A4. Nat Med. 2002;8(9):1018-1023.

19. Planagumà A, Kazani S, Marigowda G, et al. Airway lipoxin A4 generation and lipoxin $\mathrm{A} 4$ receptor expression are decreased in severe asthma. Am J Respir Crit Care Med. 2008;178(6):574-582.

20. Hashimoto A, Murakami Y, Kitasato H, Hayashi I, Endo H. Glucocorticoids co-interact with lipoxin A4 via lipoxin A4 receptor (ALX) up-regulation. Biochem Pharmacol. 2007;61:81-85.

21. Polosa R, Holgate ST. Comparative airway response to inhaled bradykinin, kallidin, and [des-Arg9] bradykinin in normal and asthmatic subjects. Am Rev Respir Dis. 1990;142:1367-1371.

22. Kips JC, Lefebvre RA, Peleman RA, Joos GF, Pauwels RA. The effect of a nitric oxide synthase inhibitor on the modulation of airway responsiveness in rats. Am J Respir Crit Care Med. 1995;151:1165-1169.

23. Figini M, Ricciardolo FL, Javdan P, et al. Evidence that epitheliumderived relaxing factor released by bradykinin in the guinea pig trachea is nitric oxide. Am J Respir Crit Care Med. 1996;153: 918-923.

24. Ricciardolo FL, Nadel JA, Yoshihara S, Geppetti P. Evidence for reduction of bradykinin-induced bronchoconstriction in guinea-pigs by release of nitric oxide. Br J Pharmacol. 1994;113:1147-1152.

25. Homma T, Irvin CG. Bradykinin-induced bronchospasm in the rat in vivo: a role for nitric oxide modulation. Eur Respir J. 1999;13:313-320.

26. Barnes PJ, Chung KF, Page CP. Inflammatory mediators of asthma: an update. Pharmacol Rev. 1998;50(4):515-596.

27. Kharitonov SA, Yates D, Robbins RA, Logan-Sinclair R, Shinebourne EA, Barnes PJ. Increased nitric oxide in exhaled air of asthmatic patients. Lancet. 1994;343:133-135.

28. Brazil C [webpage on the Internet]. Diretriz brasileira para o cuidado e a utilização de animais para fins científicos e didáticos. Brasília DF, Brazil; 2013: 1-50. Available from: http://www.cobea.org.br/arquivo/ download?ID_ARQUIVO=20. Accessed March 14, 2016.
29. Landgraf MA, Landgraf RG, Jancar S, Fortes ZB. Influence of age on the development of immunological lung response in intrauterine undernourishment. Nutrition. 2008;24:262-269.

30. Hampl V, Waters CL, Archer SL. Determination of nitric oxide by the chemiluminescence reaction with ozone. In: Feelisch M, Stamler JS, editors. Methods in Nitric Oxide Research. New York, NY: John Wiley and Sons Ltd.; 1996:309-318.

31. Landgraf RG, Russo M, Jancar S. Acute inhibition of inducible nitric oxide synthase but not its absence suppresses asthma-like responses. Eur J Pharmacol. 2005;518(2-3):212-220.

32. Silva RC, Landgraf MA, Hiyane MI, Pacheco-Silva A, Câmara NO, Landgraf RG. Leukotrienes produced in allergic lung inflammation activate alveolar macrophages. Cell Physiol Biochem. 2010;26(3):319-326.

33. Oudart H, Groscolas R, Calgari C, et al. Brown fat thermogenesis in rats fed high-fat diets enriched with n-3 polyunsaturated fatty acids. Int J Obes Relat Metab Disord. 1997;21:955-962.

34. Serhan CN, Yacoubian S, Yang R. Anti-inflammatory and proresolving lipid mediators. Annu Rev Pathol. 2008;3:279-312.

35. Soehnlein O, Lindbom L. Phagocyte partnership during the onset and resolution of inflammation. Nat Rev Immunol. 2010;10:427-439.

36. Calder PC. Omega-3 fatty acids and inflammatory processes. Nutrients. 2010;2(3):355-374.

37. Barros KV, Carvalho PO, Cassulino AP, et al. Fatty acids in plasma, white and red blood cells, and tissues after oral or intravenous administration of fish oil in rats. Clin Nutr 2013; 32(6):993-998.

38. González-Périz A, Horrillo R, Ferré N, et al. Obesity-induced insulin resistance and hepatic steatosis are alleviated by omega- 3 fatty acids: a role for resolvins and protectins. FASEB $J$ 2009; 23(6): 1946-1957

39. Lopez AF, Sanderson CJ, Gamble JR, Campbell HD, Young IG, Vadas MA. Recombinant human interleukin-5 is a selective activator of human eosinophil function. J Exp Med. 1988;167:219-224.

40. Corren J. Inhibition of interleukin-5 for the treatment of eosinophilic diseases. Discov Med. 2012;13(71):305-312.

41. Steinke JW, Borish L. Th2 cytokines and asthma. Interleukin-4: its role in the pathogenesis of asthma, and targeting it for asthma treatment with interleukin-4 receptor antagonists. Respir Res. 2001;2:66-70.

42. Bryborn M, Adner M, Cardell LO. Interleukin-4 increases murine airway response to kinins, via up-regulation of bradykinin B1-receptors and altered signalling along mitogen-activated protein kinase pathways. Clin Exp Allergy. 2004;34:1291-1298.

43. Barnes PJ. Effect of bradykinin on airway function. Agents Actions Suppl. 1992;38(pt 3):432-438.

44. Kharitonov SA, Sapienza MM, Chung KF, Barnes PJ. Prostaglandins mediate bradykinin-induced reduction of exhaled nitric oxide in asthma. Eur Respir J. 1999;14(5):1023-1027.

45. Ricciardolo FL, Timmers MC, Geppetti P, et al. Allergen-induced impairment of bronchoprotective nitric oxide synthesis in asthma. J Allergy Clin Immunol. 2001;108:198-204.

46. Perretti M, D'Acquisto F. Annexin A1 and glucocorticoids as effectors of the resolution of inflammation. Nat Rev Immunol. 2009;9: $62-70$.

47. Sawmynaden P, Perretti M. Glucocorticoid upregulation of the annexin-A1 receptor in leukocytes. Biochem Biophys Res Commun. 2006;349:1351-1355.

48. Goulding NJ, Godolphin JL, Sharland PR, et al. Anti-inflammatory lipocortin 1 production by peripheral blood leucocytes in response to hydrocortisone. Lancet. 1990;335:1416-1418.

49. Liu Y, Cousin JM, Hughes J, et al. Glucocorticoids promote nonphlogistic phagocytosis of apoptotic leukocytes. J Immunol. 1999;162: 3639-3646.

50. Levy BD, Lukacs NW, Berlin AA, et al. Lipoxin A4 stable analogs reduce allergic airway responses via mechanisms distinct from CysLT1 receptor antagonism. FASEB J. 2007;21:3877-3884.

51. Levy BD, Bonnans C, Silverman ES, et al. Diminished lipoxin biosynthesis in severe asthma. Am J Respir Crit Care Med. 2005;172:824-830. 
52. Gobbetti T, Ducheix S, le Faouder P, et al. Protective effects of n- 6 fatty acids-enriched diet on intestinal ischaemia/reperfusion injury involve lipoxin A4 and its receptor. Br J Pharmacol. 2015;172(3):910-923.

53. Mickleborough TD. Dietary omega-3 polyunsaturated fatty acid supplementation and airway hyperresponsiveness in asthma. J Asthma. 2005;42(5):305-314.
54. Sala-Vila A, Miles EA, Calder PC. Fatty acid composition abnormalities in atopic disease: evidence explored and role in the disease process examined. Clin Exp Allergy. 2008;38:1432-1450.

Journal of Inflammation Research

\section{Publish your work in this journal}

The Journal of Inflammation Research is an international, peer-reviewed open-access journal that welcomes laboratory and clinical findings on the molecular basis, cell biology and pharmacology of inflammation including original research, reviews, symposium reports, hypothesis formation and commentaries on: acute/chronic inflammation; mediators of inflamma-
Dovepress

tion; cellular processes; molecular mechanisms; pharmacology and novel anti-inflammatory drugs; clinical conditions involving inflammation. The manuscript management system is completely online and includes a very quick and fair peer-review system. Visit http://www.dovepress.com/ testimonials.php to read real quotes from published authors.

Submit your manuscript here: http://www.dovepress.com/journal-of-inflammation-research-journal 